\title{
Ultrastructural Analysis of Radiation Induced Chromosome Breaks and Rearrangements
}

\author{
J. L. Fernández ${ }^{1,2}$, A. Campos ${ }^{2}$, D. Cajigal ${ }^{2}$ and V. J. Goyanes ${ }^{1,2}$ \\ ${ }^{1}$ Oncology Center of Galicia, La Coruña, Spain. \\ 2Section of Genetics, Teresa Herrera Hospital. La Coruna, Spain
}

Accepted May 11, 1990

Light microscopy studies on chromosome breaks and rearrangements have provided some information about organization of the chromatin fiber within the chromosome. It has been reported that spontaneous, radiation-induced chromosome breaks as well as structural rearrangements show a non-random distribution between chromosomes and chromosome arms (Bauchinger and Götz 1979, Moore 1979, Cermeño and Lacadena (1985). Also cytogenetic data on tumor cells show rearrangements that exhibit a non-random involvement of some chromosomes and hot beak-points (Yunis 1983, Changanti and Koduru 1987) along chromatids. Futhermore, chromosome fragile sites were described as regions expressed as chromatid or isochromatid breaks or gaps under certain cell culture conditions or following treatment with particular chemicals (Sutherland and Hecht 1985). Distribution of break-points in constitutional chromosome rearrangements in tumor cells has a possible relationship with the chromosome position of fragile sites, which would contribute to their genesis (Yunis 1986). In fact, fragile sites behave as targets for some mutagens and carcinogens, including ionizing radiation (Yunis et al. 1987).

Other chromosomal phenomenon where breaks are involved are Sister-Chromatid Exchanges (SCE). It consists of the reciprocal and symmetrical exchange between the two sister chromatids, which is produced during replication-modulation of DNA (Taylor 1957). Their frequency increases when cells are exposed to mutagens and carcinogens, being the most sensitive cytological method to detect potential clastogenic agents (Schvartzman 1987). A non-random distribution of SCE within chromosomes has been reported (Kato 1979, Dimitrov 1986) and it has been recently proposed that fragile sites are hot spots not only for chromosomal lesions but also for SCE formation (Glover and Stein 1987).

In order to explore the probable relationship between the characteristics of chromosome breaks-rearrangements with the several levels of chromatin fiber organization of the metaphase chromosome, here we present and ultrastructural approach on gamma-irradiated Chinese DON cells. Chromosome breaks an rearrangements were examined by transmission electron microscopy employing a variety of whole mounting or thin sectioning procedures. Furthermore, the angle of the border of breakage with respect to the chromosome axis was measured in whole-mounted chromosomes where DNA-breaks were performed by a photoinduction technique (Fernández et al. in press).

\section{Material and methods}

\section{Condensation-inhibition of G-bands and cell irradiation}

Chinese Hamster DON cells were exponentially growing in the dark at $37^{\circ} \mathrm{C}$ in RPMI medium supplemented with $15 \%$ fetal calf serum, $100 \mathrm{UI} / \mathrm{ml}$ penicillin, $100 \mu \mathrm{g} / \mathrm{ml}$ streptomycin and $2 \mathrm{mM}$ L-glutamine. Treatment by BrdU $(20 \mu \mathrm{g} / \mathrm{ml})$ and Hoechst $33258(40 \mu \mathrm{g} / \mathrm{ml})$ was performed for $12 \mathrm{hr}$, and $300 \mathrm{cGy}$ of gamma-radiation (from a ${ }^{\circ 0} \mathrm{Co}$ source, Theratron 780 , 
Canada) were administered $2 \mathrm{hr}$ before harvesting. Cells were arrested at metaphase for $3 \mathrm{hr}$ with $0.5 \mu \mathrm{g} / \mathrm{ml}$ colchicine and mitosis were preferentially detached from the monolayer by being gently shaken off the culture flasks. After harvesting, mitosis were hypotonically treated for $10 \mathrm{~min}$ at $37^{\circ} \mathrm{C}$ with $0.075 \mathrm{M} \mathrm{KCl}$.

\section{Isolation and whole-mounting}

Mitotic cells hypotonically treated were centrifuged at $1200 \mathrm{rpm}$ for $5 \mathrm{~min}$ and the pellet covered with $2 \mathrm{ml}$ of acid isolation buffer ( $1 \%$ citric acid, $1 \%$ Triton $\mathrm{X}-100,6 \mathrm{mM} \mathrm{MgCl}$ ) and left at room temperature for $30 \mathrm{~min}$. The cells were gently syringed 7-10 times through a No. 22-gauge needle and the chromosome isolation monitored by phase microscopy. The chromosome suspension was again centrifuged for $5 \mathrm{~min}$ at $2000 \mathrm{rpm}$ through a cushion of isolation acid buffer onto Formvar-coated EM grids, which were immediately immersed into $50 \%$ ethanol for $10 \mathrm{~min}$. After two 5-min steps in $75 \%$ and $100 \%$ ethanol, the grids were immersed into two $5 \mathrm{~min}$ baths of $100 \%$ amyl acetate and air-dried. Electron microscopic examination and photographic recording were performed with a Zeiss 109 Turbo EM operated at $50 \mathrm{kV}$.

\section{Embedding and sectioning}

Chromosomes were embedded and thin sectioned according the procedure previously described (Goyanes and Schvartzman 1983). In brief, irradiated Chinese Hamster DON cells (without BrdU-Hoechst 33258 treatment) growing in monolayers, were treated for $10 \mathrm{~min}$ with hypotonic solution $(0.075 \mathrm{M} \mathrm{KCl})$ at $37^{\circ} \mathrm{C}$ in the flask, flxed with methanol: acetic acid (3: 1), and washed with acid isolation buffer for $30 \mathrm{~min}$. Care was taken to prevent detachment of the monolayer. Cells were scraped off the flasks with a rubber policeman, centrifuged at $1200 \mathrm{rpm}$ for $10 \mathrm{~min}$, and the resulting pellet covered with $8 \%$ formaldehyde in Hanks for $16 \mathrm{hr}$ at $4^{\circ} \mathrm{C}$. The cell pellet was embedded in Epon, and $0.1 \mu \mathrm{m}$ thick sections were cut with an LKB ultra-microtome. Sections were placed on 200 mesh copper grids and stained with uranyl acetate and lead citrate (Reynolds 1963).

\section{Photoinduction of DNA break-down in one of the sister chromatids}

Chinese Hamster DON cells exponentially growing were treated with $\mathrm{BrdU}(16.6 \mu \mathrm{g} / \mathrm{ml})$ for $8 \mathrm{hr}$. Then the culture medium was removed and the cells growed in a fresh medium without BrdU and with thymidine $(10 \mu \mathrm{g} / \mathrm{ml})$ for $12 \mathrm{hr}$. Colchicine $(0.5 \mu \mathrm{g} / \mathrm{ml})$ and Hoechst 33258 $(13.2 \mu \mathrm{g} / \mathrm{ml})$ were added for the last $2 \mathrm{hr}$ and $10 \mathrm{~min}$, respectively. Afterwards, cultures were exposed to a $280-313 \mathrm{~nm}$ UV-radiation for $15 \mathrm{~min}$. Finally, chromosomes were isolated and processed by whole-mounting electron microscopy technique, as described previously.

\section{Results and discussion}

Scarce information has been reported where chromosome rearrangments are related with the levels of hierarchy of the chromatin fiber organization at metaphase (Mouriquand et al. 1974, Mouriquand et al. 1975, Bahr 1978, Mace et al. 1978, Yu 1979). At this respect here we attempt several approaches of DNA-chromatin damage and their relationship with the ultrastructure of metaphase chromosomes employing preservative technique of whole-mounting EM. Also, a first quantitative approach on the break border is reported.

Position of break-points was examined by EM in rearranged chromosomes irradiated at G-2 phase of the cell cycle. In order to locate accurately the break-points along the chromatid, a high resolution R-banding pattern was induced by means of condensation-inhibition of G-bands throughout a BrdU-Hoechst 33258 treatment along S and G-2 phases (Goyanes and Méndez 1981). When examined, chromosomes showed well-preserved three-dimensional 
organization, with chromatin fibers organized in sequences of condensed and relaxed looping structures (R-bands) alternating with tracts of thightly packed longitudinally running fibers (G-bands) (Fig. 1). Condensation-inhibition was more pronounced in some G-bands than in others. This in vitro BrdU-Hoechst 33258 treatment inverts the normal pattern of packaging of the chromatin fiber within the chromosome (Bahr et al. 1973, Yunis and Bahr 1979, Goyanes and Méndez 1981) thus resulting in chromomere like R-bands intercalated with interchromomeric G-bands.

Nine from twelve rearranged chromosomes showed their breaks located at the point of transition between G- and R-bands (Figs. 1a, and b). The chromosome average diameter of break-points and rearrangements was $71.65 \%$ of the wide condensed R-bands, a result similar

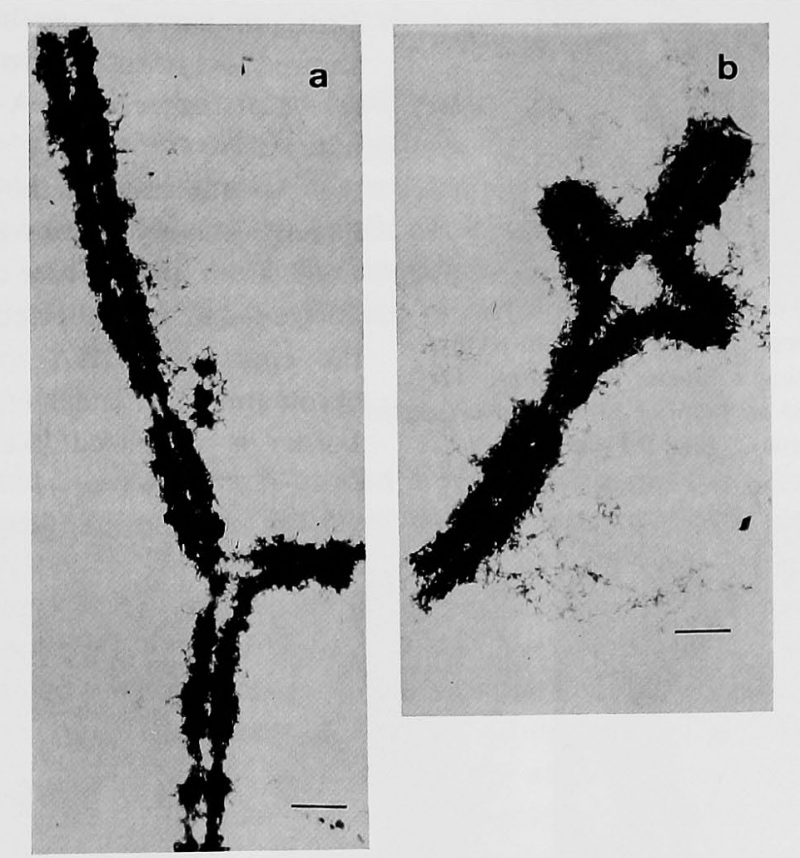

Fig. 1. a, b). Electron micrographs of chromatid-type rearrangements in chinese hamster chromosomes gamma-irradiated at G-2. Whole-mounted chromosomes show a high resolution R-banding pattern induced by condensation-inhibition of G-bands. Because sister chromatids retain strict pairing, position of break-points can be mapped. Transition between chromomeric and interchromomeric chromatin structures represents the preferential points of breakage and rearrangements. Bar: $0.5 \mu \mathrm{m}$.

to the average diameter of narrow G-bands $(69.79 \%)$. At this respect, light-microscopy analysis performed by Dutrillaux et al. (1977) showed the preferential involvement of the R-G interbands when complementary banding techniques were used for the location of the break-points. Also, Holmquist et al. (1982) argued that the junctions of R- and G-bands might be specially sensitive to breakage because of their different timing of replication (Comings 1978).

Furthermore, it has been proposed that fragile sites represent regions where DNA sequences are, or can induced to be, late-replicating during S or G-2 phases of the cell cycle, resulting in incomplete chromatin condensation. Rearrange and recombinogenecity at fragile sites would be consequence of the replication junctions that flank late-replicating DNA (Laird et al. 1987).

Chomatin fiber damage was also examined in thin sectioned chromosomes. Three chromosomes presented their broken terminal end organized as a coil (Siebert and Loidl 1984) (Fig. 
2). Measurements pointed that this coil was constituted by two $23 \mathrm{~nm}$ diameter chromatin fibers coiling together, showing $38.09 \mathrm{~nm}$ average width. This results support the hypothesis that coils should be excentrically located to constitute the chromatid, because coils diameter was $43.70 \%$ of the mean chromatid diameter.

Another most exciting data can be deduced of characteristics of the border of breakage of the chromatid. This border was examined in whole-mounted chromosomes where DNAbreaks were photoinduced. Photoinduction technique is based on the ability of UV-radiation to induce extensive single breaks in BrdU

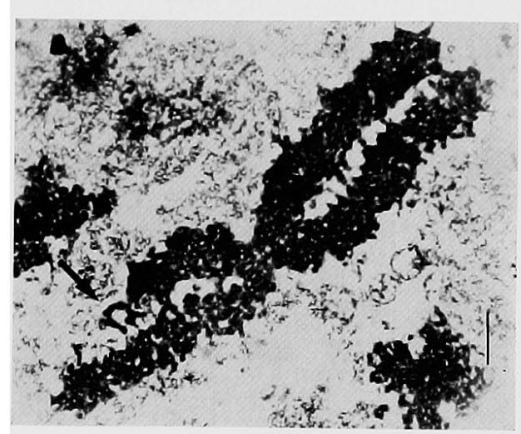

Fig. 2. Electron micrograph of an ultrathin sectioned chromosome showing a broken chromatid. Terminal end is organized as a coil of $38.09 \mathrm{~nm}$ average width (arrow). Bar: $0.5 \mu \mathrm{m}$. substituted DNA strand after a brief Hoechst 33258 treatment (Matsukuma and Utakoji 1984). Chromosomes which incorporated BrdU in part of one of their chromatids showed loss or dispersion of chromatin fibers at the places were DNA-breaks were photoinduced.

As ionizing radiation, photoinduced damage mainly expresses as DNA affectation. Then, the "border of damage" between affected and non-affected chromatin defines the course of DNA molecule within the chromatid (Fernández et al. in press). This border is visualized like a sharp break in

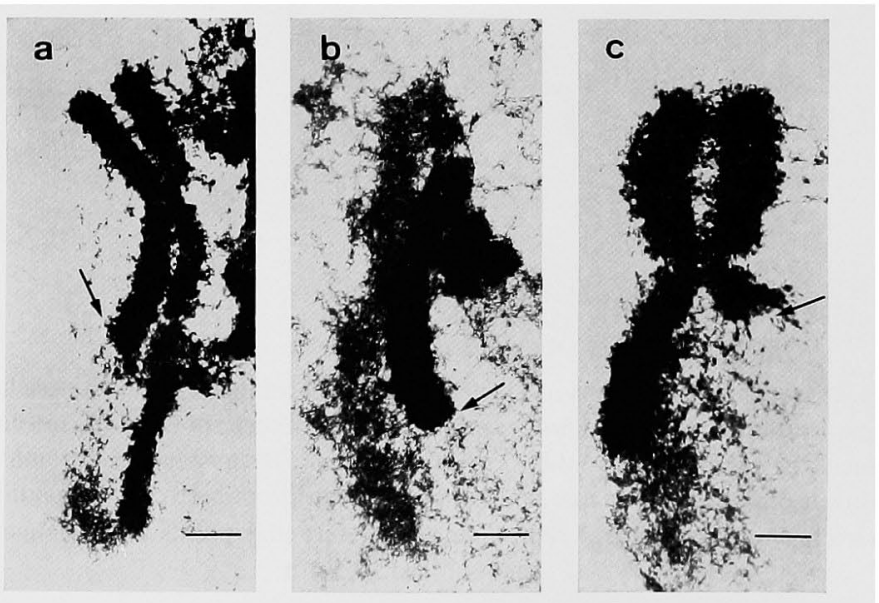

Fig. 3. Electron micrographs of whole-mounted chromosomes where breaks were photoinduced in BrdU-substituted DNA. Affected chromatin appears lost or widely dispersed. The border of damage (arrow) defines the course of DNA molecule within the chromatid. a) Early condensed chromosome. b) and c). High condensed chromosomes. The angle of the border of damage with respect to the chromatid axis tends to be more perpendicular as condensation is progressing. Bar: $0.5 \mu \mathrm{m}$.

hardly affected samples, where damaged chromatin was widely dispersed or lost (Figs. 3a, b, c).

To establish the angle of the border of breakage with respect to the chromatid axis, 23 breaks were measured in 16 whole-mounted chromosomes with photoinduced DNA-breaks. Forteen breaks from 11 early condensed chromosomes presented an average angle of $69.43^{\circ}$, while 9 break-borders from 5 high condensed chromosomes showed $78.22^{\circ}$ (Fig. 3 ). Then, as Goyanes and Schvartzman (1983) pointed about the "border of exchange" in SCE, the tilting 
degree of the breakage-border with respect to the chromatid axis is dependent on the chromosome condensation level, tending to be more perpendicular as condensation is progressing, possibly by a coiling packing mechanism.

Our results suggest that DNA break-down at any of the interphase stages of the cell kinetic cycle deeply influences the higher order structure of the mitotic chromosome. Also, the border of breakage, besides representing the ending tract of the chromatin fiber, constitutes a hot point for chromosome linkage with other chromatid fragments. The fact that broken ends are unstable and sticky is clearly viewed in chromosomes where part of chromatin was removed by photoinduced DNA-breaks (Fernández et al. in press).

The interphase between G- and R-bands, that is to say between chromomeric and interchromomeric chromatin structures, represents the change between a coiled to a longitudinal pattern of organization. These interphases show to be critical and fragile spots places for breakage and rearrangements.

The eukariotic chromosome can be considered as a long chromatin fiber that generates a three-dimensional volume in mitosis as a consequence of a programmated folding in space and time (Goyanes 1985). Chromosomal differentiated regions would be constituted by segments of specific DNA sequences and or characteristic non-histone associated proteins, with their own transcriptional, replication and condensation behaviour. Transition points between these stretches would represent the preferential points of chromosomal breakage-rearrangements.

\section{Abstract}

Chinese Hamster chromosomes R-banded in vitro were gamma-irradiated and chromatid breaks and rearrangements examined by electron microscopy employing whole-mounting tech nique. Breaks were preferentially located at the point of transition between G- and R-bands where the chromosome showed an average diameter $71.65 \%$ of the wide condensed R-bands. This result was similar to the average diameter of narrow G-bands. Three chromosomes which were thin sectioned presented their broken terminal end organized as a coil constituted by two $23 \mathrm{~nm}$ wide chromatin fibers coiling together. Coils diameter was $43.70 \%$ of the mean chromatid diameter. The border of damage-breakage was analyzed in whole-mounted chromosomes where breaks were photoinduced in BrdU-substituted DNA. Measurements of the angle of the sharp border of damage with respect to the chromatid axis showed a tendency to be more perpendicular as condensation progressed. These results clearly correlate with the several levels of chromatin fiber organization of the metaphase chromosome.

\section{References}

Bahr, G. F., Mikel, V. and Engler, W. F. 1973. Correlates of chromosomal banding at the level of ultrastructure. In: Chromosome Identification, Nobel Symposium 23, T. Caspersson and L. Zech, eds. Academic Press, New York, 280-289.

- 1978. Considerations of the structure of chromosomes and chromatin in relation to chromosomal aberrations. Virchows Arch. B. Cell Path., 29: 3-14.

Bauchinger, M. and Götz, G. 1979. Distribution of radiation induced lesions in human chromosomes and dose-effect relation analysed with G-banding. Rad. and Environm. Biophys. 16: 355-366.

Cermeno, M. C. and Lacadena, J. R. 1985. C-banding analysis of gamma-radiation induced chromosomal interchanges in rye. The role of $\mathrm{C}$-heterochromatin in chromosome repatterning. Chromosoma 91: 297-306.

Comings, D. E. 1978. Mechanisms of chromosome banding and implications for chromosome structure. Ann. Rev. Genet. 12: 25-46.

Chaganti, R. S. K. and Kodoru, P. R. K. 1987. Patterns of chromosome breakage in non-Hodgkin lymphoma: significance to gene alteration in tumorigenesis. Cytogenet. Cell Genet. 45: 93-98. 
Dimitrov, B. 1986. Relationship between sister-chromatid exchanges and heterochromatin on DNA replication in chromosomes of Crepis capillaris. Mutat. Res. 190: 271-276.

Dutrillaux, B., Couturier, J., Viegas-Pequignot, E. and Schaison, G. 1977. Localization of chromatid breaks in Fanconi's anemia using three consecutive stains. Hum. Genet. 37: 65-71.

Fernández, J. L., Costas, E. and Goyanes, V. J. Chromosome structure and condensation in relation to DNA integrity. Cytobios, in press.

Glover, T. W. and Stein, C. K. 1987. Induction of Sister Chromatid Exchanges at common fragile sites. Am. J. Hum. Genet, $41: 882-890$.

Goyanes, V. J. and Méndez, J. 1981. Karyotyping chromosomes by electron microscopy. Condensation-inhibition of $\mathrm{G}$ bands in human and chinese hamster chromosomes by a BrdU-Hoechst 33258 treatment. Cancer Genet. Cytogenet. 4: 45-51.

- and Schvartzman, J. B. 1983. Electron microscopy of sister chromatid exchanges? Cytogenet. Cell Genet. 36: 612-616.

- 1985. Electron microscopy of chromosomes. Towards an ultrastructural cytogenetics. Cancer Genet. Cytogenet. 15: 349-367.

Holmquist, G., Gray, M, Porter, T. and Jordan, J. 1982. Characterization of Giemsa dark- and light-band DNA. Cell. $31: 121-129$.

Laird, CH., Jaffe, E., Karpen, G., Lamb, M. and Nelson, R. 1987. Fragile sites in human chromosomes as regions of late-replicating DNA. Trends In Genetics 3: 274-281.

Mace, M. L., Daskal, Y. and Wray, W. 1978. Scanning-electron microscopy of chromosome aberrations. Mutat. Res. 52: 199-206.

Matsukuma, S, and Utakoji, T. 1984. Photo-induced break down and chromosome structure. In: Chromosomes Today. M. D. Bennett, A. Gropp, V. Wolf Eds. Vol. 8. George Allen and Unwin 1td. London, pp. 324.

Moore, R. C. 1979. Studies of X-rays induced chromosome aberrations in cells of the blactailed wallaby. I Nonrandom exchanges in peripheral blood cells irradiated in Go. Mutat. Res. 59: 203-208.

Mouriquand, C., Gilly, C. et Wolff, C. 1974. Etude ultrastructurale sur chromosome entier d'anomalies radioinduites I. Lésions des chromatides. Biomedicine $21: 414-419$.

— and - 1975. Etude ultrastructurale sur chromosome entier d'anomalies radio-induites II. Remaniements et fragments. Ann. Génét. 18: 29-34.

Kato, H. 1979. Preferential occurrence of sister chromatid exchanges at heterochromatin-euchromatin junctions in the wallaby and hamster chromosomes. Chromosoma 74: 307-316.

Reynolds, E. S. 1963. The use of lead citrate high pH as an electron opaque stain in electron microscopy. J. Cell Biol. 17: 208-212.

Siebert, E. and Loidl, J. 1984. Some considerations on metaphase chromosome-coils. In: Chromosomes today. M. D. Bennett, A. Gropp, V. Wolf eds, vol 8. George Allen and Unwin, 1td. London, p. 341.

Schvartzman, J. B. 1987. Sister-Chromatid Exchanges in higher plant cells: past and perspectives. Mutat. Res. $181: 127-145$.

Sutherland, G. R. and Hecht, F. 1985. Fragile sites on Human Chromosomes. Oxford Monographs on Medical Genetics, No 13. New York: Oxford University Press.

Taylor, J. H., Woods, P. S. and Highes, W. L. 1957. The organization and duplication of chromosomes as revealed by autoradiographic studies using tritium-labelled thymidine. Proc. natn. Acad. Sci. USA 43: 122-128.

Yu, C. K. 1979. Morphology of chromosomal aberrations viewed by scanning electron microscopy. Cytologia 44: $669-677$.

Yunis, J. J. and Bahr, G. F. 1979. Chromatin fiber organization of human interphase and prophase chromosomes. Exp. Cell Res. 122: 63-72.

- 1983. The chromosomal basis of human neoplasia. Science 221: 227-236.

- 1986. Chromosomal rearrangements, genes, and fragile sites in cancer. Clinical and biological implications. In: De vita VT, Hellman S, Rosenberg SA (eds). Important Advances in Oncology 1986. J. R. Lippincott Co. Philadelphia, Pennsylvania, pp. 93-128.

-, Soreng A. L. and Bowe, A. E. 1987. Fragile sites are targets of diverse mutagens and carcinogens. Oncogene 1: 59-69. 